\title{
Peningkatan Nilai Jual Golla Mamea Melalui Pengemasan Yang Menarik Serta Tahan Simpan Pada Kelompok Wanita Tani Melati Desa Mosso Kecamatan Balanipa Kabupaten Polewali Mandar
}

\author{
Nurhidayah $^{1)}$, Dahlia $^{2}$, Ikawati $^{3)}$ \\ 12)3) Universitas Sulawesi Barat, Majene Indonesia
}

Corresponding Author: Nurhidayah, nurhidayah@unsulbar.ac.id

\begin{abstract}
Abstrak: Masyarakat Desa Mosso merupakan masyarakat yang produktif dalam pengelolaan hasil tani seperti aren, cokelat, kelapa dan hasil tani lainnya. Program pengabdian ini berfokus pada hasil aren yang dikelola menjadi golla mamea organik atau secara umum lebih dikenal dengan gula merah organik yang selalu dicari dan dijadikan oleh-oleh turis lokal ketika berkunjung ke wilayah mandar, hampir seratus persen warga desa Mosso memiliki keahlian bahkan menjadikan pembuatan golla mamea sebagai mata pencaharian, hanya saja kemasan golla mamea belum ada inovasi sejak diproduksi oleh nenek moyang sehingga wilayah pemasaran produk golla mamea masih terbatas dan daya tahan simpan yang rendah, Tujuan program pengabdian ini ialah membantu masyarakat pembuat golla mamea desa Mosso dalam mengatasi masalah pengemasan sehingga setelah selesainya pengabdian ini dapat dihasilkan kemasan yang menarik dan memiliki daya tahan simpan. Adapun Target pengabdian adalah masyarakat Desa Mosso khususnya pembuat golla mamea dapat menghasilan produk yang lebih unggul dan bernilai jual. Untuk mencapai target dan penyelesaian masalah dari program Pengabdian ini menggunakan pendekatan Participatory Rural Appraisal (PRA) dengan metode pelatihan mengenai budidaya pertanian aren, simulasi pembuatan produk dan pengemasannya serta pendampingan guna menumbuhkan semangat dan jiwa kewirausahaan dan strategi pemasaran bagi wanita tani. Pelaksanaan program dilakukan pada hari kamis 6 agustus 2020. Setelah dilaksanakannya program kemitraan masyarakat stimulus ini diperoleh produk golla mamea dengan kemasan yang lebih menarik dan memiliki daya tahan simpan serta terjaga kebersihannya, dengan adanya kemasan baru ini nilai jual golla mamea yang sebelumnya bearada pada kisaran Rp 8.000 dapat dijual hingga Rp 13.000 dengan packaging yang baru. Selain itu adanya penambahan wawasan mengenai pertanian aren memberikan motivasi untuk memelihara atau budidaya pohon aren sebagai bahan dasar pembuatan golla mamea yang diwariskan oleh nenek moyang
\end{abstract}

Kata Kunci: Golla Mamea, Kemasan, Mandar

Abstract: The people of Mosso Village are productive in the management of agricultural products such as sugar palm, cocoa, coconut and other agricultural products. This service program focuses on the results of palm sugar which are managed into organic golla mamea or generally known as organic brown sugar which is always sought after and used by local tourists when visiting the mandar area, almost one hundred percent of Mosso villagers have the expertise to even make golla. mamea as a livelihood, it's just that the golla mamea packaging has not been innovated since it was produced by the ancestors so that the marketing area of the golla mamea product is still limited and the shelf life is

Submitted: 13.8.2020, Revised: 27.10.2020, Accepted: 28.10 .2020 
low. after the completion of this service can produce attractive packaging and have shelf life. The target of community service is that the people of Mosso Village, especially those who make golla mamea, can produce superior and valuable products. To achieve targets and solve problems from this Community Service program using the Participatory Rural Appraisal (PRA) approach with training methods on sugar palm cultivation, simulation of product manufacture and packaging and assistance to foster an entrepreneurial spirit and spirit and marketing strategies for female farmers. The program was implemented on Thursday 6 August 2020. After the implementation of this stimulus community partnership program, golla mamea products were obtained with more attractive packaging and durability and cleanliness, with this new packaging the selling value of golla mamea which previously was around Rp. 8,000 can be sold up to Rp. 13,000 with new packaging. In addition, the addition of insight into sugar palm farming provides motivation to maintain or cultivate palm trees as the basic material for making golla mamea which was passed down from our ancestors.

Keywords: Golla Mamea, Packaging, Mandar

\section{Pendahuluan}

Kabupaten Polewali Mandar merupakan salah satu wilayah yang ada di Provinsi Sulawesi Barat, dimana sebagian besar penduduknya adalah suku Mandar. Kabupaten Polewali Mandar memiliki ciri khas tersendiri, representasi dari kekhasan tersebut dapat berupa adat istiadat, bahasa, tempat wisata, kuliner dan sebagainya. Ciri khas tersebut secara alami lahir sesuai dengan keadaan lingkungan.

Salah satu kecamatan yang ada di Kabupaten Polewali Mandar adalah Kecamatan Balanipa. Adapun luas wilayah kecamatan balanipa yaitu adalah $37,42 \mathrm{~km}^{2}$ atau sekitar 1,85\% dari keseluruhan wilayah Kabupaten Polewali Mandar, jarak tempuh sekitar 60 menit dari kota Majene memiliki 25.678 jiwa penduduk dan 5.541 rumah tangga yang dinaungi oleh 11 desa (BPS, 2016). Salah satu desa yang dikecamatan Balanipa yaitu Desa Mosso yang menjadi wadah untuk melaksanakan pengabdian kepada masyarakat ini. Desa Mosso Dengan lokasinya yang berada diketinggian merupakan sentra penghasil Gula merah cetak yang terkenal di Provinsi Sulawesi Barat andalan masyarakat Kecamatan Balanipa karena rasa manisnya yang khas dan bebas dari bahan pengawet. Desa mosso memiliki 3 dusun penghasil gula yaitu Dusun Pangalloang, Dusun Mosso dan Dusun Naung Landi.

Pohon aren merupakan salah satu jenis tumbuhan palma yang memproduksi buah, nira dan pati atau tepung di dalam batang. Hasil produksi aren ini semuanya dapat dimanfaatkan dan memiliki nilai ekonomi. Akan tetapi hasil produksi aren yang banyak diusahakan oleh masyarakat adalah nira yang diolah untuk menghasilkan gula aren dan produk ini memiliki pasar yang sangat luas. Negara-negara yang membutuhkan gula aren dari Indonesia adalah Arab Saudi, Amerika Serikat, Australia, Selandia Baru, Jepang dan Kanada (Sapari. A, 1994) Aren merupakan jenis tanaman tahunan, berukuran besar, berbentuk pohon soliter tinggi hingga $12 \mathrm{~m}$, diameter setinggi dada (DBH) hingga 60 (A. Sapari, 1994). Pohon aren dapat tumbuh mencapai tinggi dengan diameter batang sampai $65 \mathrm{~cm}$ dan tinggi $15 \mathrm{~m}$ bahkan mencapai $20 \mathrm{~m}$ dengan tajuk daun yang menjulang di atas batang (Soeseno. S, 1991). Rasa manis pada nira aren disebabkan kandungan karbohidratnya mencapai $11,28 \%$. Nira yang baru menetes dari tandan bunga mempunyai $\mathrm{pH}$ sekitar 7 atau $\mathrm{pH}$ netral, akan tetapi pengaruh keadaan sekitarnya menyebabkan nira aren mudah terkontaminasi dan mengalami fermentasi sehingga rasa manis pada nira aren cepat berubah menjadi asam atau $\mathrm{pH}$ menurun (Lempang, 2006) 
Hampir semua bagian pohon aren bermanfaat dan dapat digunakan untuk berbagai kebutuhan, mulai dari bagian fisik (akar, batang, daun, ijuk dll) maupun hasil produksinya (nira, pati/tepung dan buah). nira aren segar juga terutama digunakan sebagai bahan baku pengolahan gula aren. Pengolahan nira secara langsung setelah diturunkan dari pohon menghasilkan gula 104,8 gram per liter nira atau rendemen produksi 10,48\% (Lempang, 2012)

Golla mamea yang lebih dikenal dengan istilah umum gula merah merupakan salah satu produk yang dihasilkan masyarakat desa Mossso dari hasil pertanian tanama aren yang memang banyak tumbuh dan dimiliki oleh masyarakat desa Mosso. Mayoritas warga di desa Mosso bekerja sebagai petani sekaligus pembuat gula merah rumahan. Untuk pembuatan biasanya masyarakat membuat hampir setiap harinya. Adapun harga jual gula merah cetak sifatnya bervariasi tergantung pada ukuran gula merah harganya berada pada kisaran Rp 8.000 s/d Rp 10.000/ Buah.

Kelompok Wanita Tani "Melati” yang beralamat di Desa Mosso Kecamatan Balanipa Kabupaten Polewali Mandar yang merupakan mitra dalam pengabdian ini memiliki anggota sebanyak 25 orang yang semuanya merupakan pembuat gula merah yang memproduksi gula merah dengan skala Home industries. Produksi gula merah didesa tersebut dilakukan karena di latar belakangi oleh kondisi alam desa mosso banyak ditumbuhi pohon aren sehingga masyarakat mengolahnya menjadi produk yang bernilai jual. Dengan usaha yang dilakukan oleh masyarakat tersebut sehingga desa mosso dikenal sebagai sentra penghasil gula merah. Adapun yang menjadi keunggulan dari gula olahan Desa Mosso yaitu gula ini merupakan gula organik yang $100 \%$ alami bebas dari bahan pengawet. Gula aren juga banyak dikonsumsi sebagai salah satu bahan pemanis alami yang sangat aman bagi tubuh. Selain itu kandungan didalam gula aren ini cukup penting peranannya untuk membantu memenuhi kebutuhan tubuh akan nutrisi tertentu. Beberapa manfaat diantaranya yaitu mengandung antioksidan, mencegah anemia, meningkatkan daya tahan tubuh dan menormalkan kolesterol. Berdasarkan observasi awal yang telah dilakukan, Desa Mosso menunjukan bahwa hampir semua warga memiliki kebun aren masing-masing untuk dipanen air niranya sebagai bahan baku utama pembuatan gula merah yang dalam pembuatannya dapat dilakukan secara perorangan maupun secara kelompok. Berikut gambar area perkebunan aren masyarakat Desa Mosso.
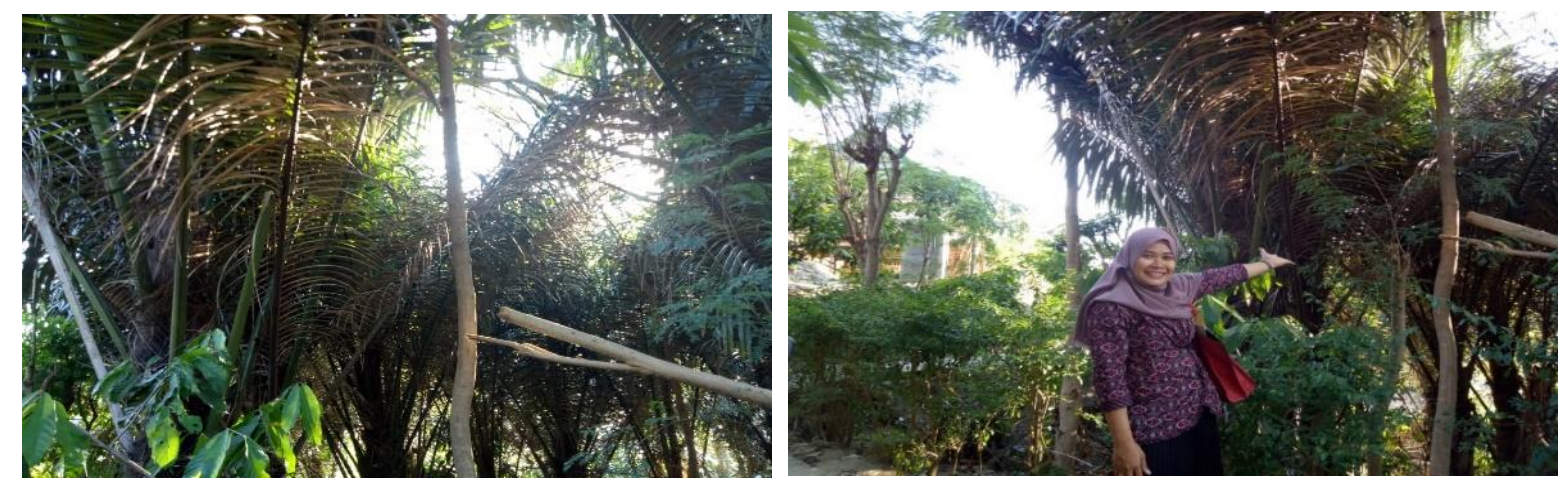


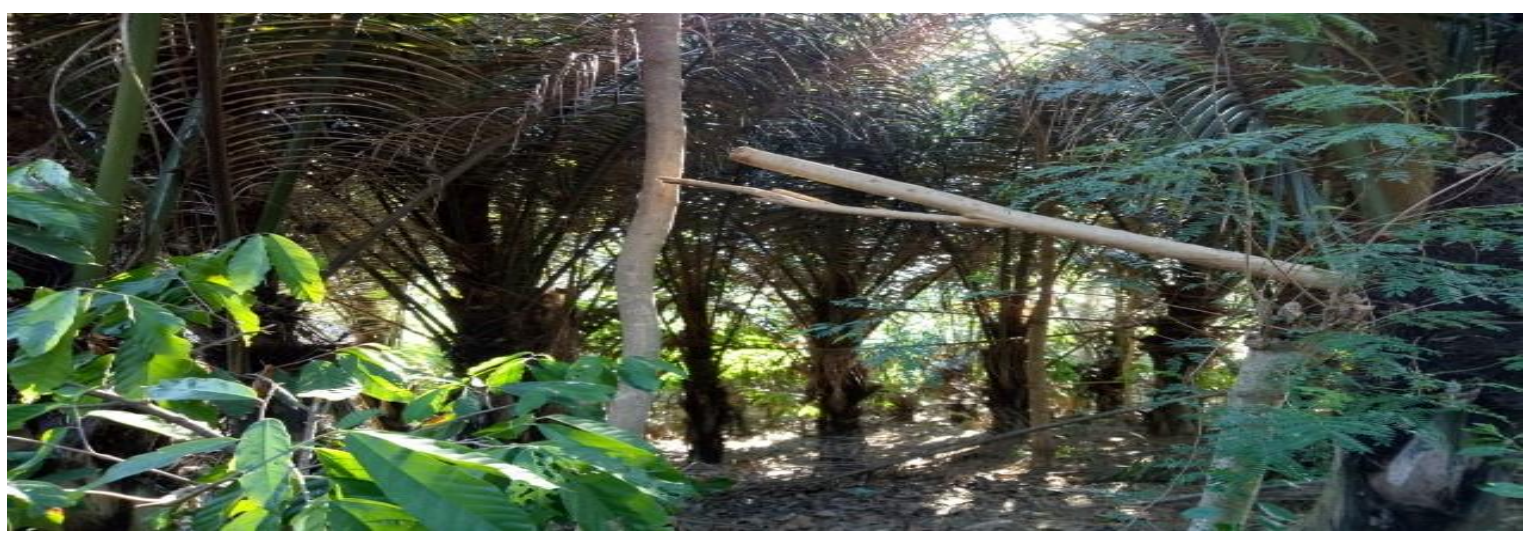

Gambar 1. Area perkebunan pohon aren

Walaupun usaha pengolahan gula merah telah berlangsung lama dilakukan oleh masyarakat Desa Mosso namun belum dapat meningkatkan pendapatan maupun kesejahteraan masyarakat hal tersebut disebabkan karena pola pengelolaannya masih sangat tradisional, keterbatasan pemanfaatan teknologi dan keterbatasan pendidikan masyarakat. Warga masyarakat yang menghasilkan gula merah bisanya menjual produknya langsung ke pasar terdekat atapun dikumpulkan di kelompok tani untuk dijual secara bersama-sama. Berikut ini disajikan proses pengemasan golla mamea tradisional yang selama ini dilakukan oleh mitra serta sebagain perlengkapan yang digunakan dan bentuk golla mamea yang siap dijualkan.
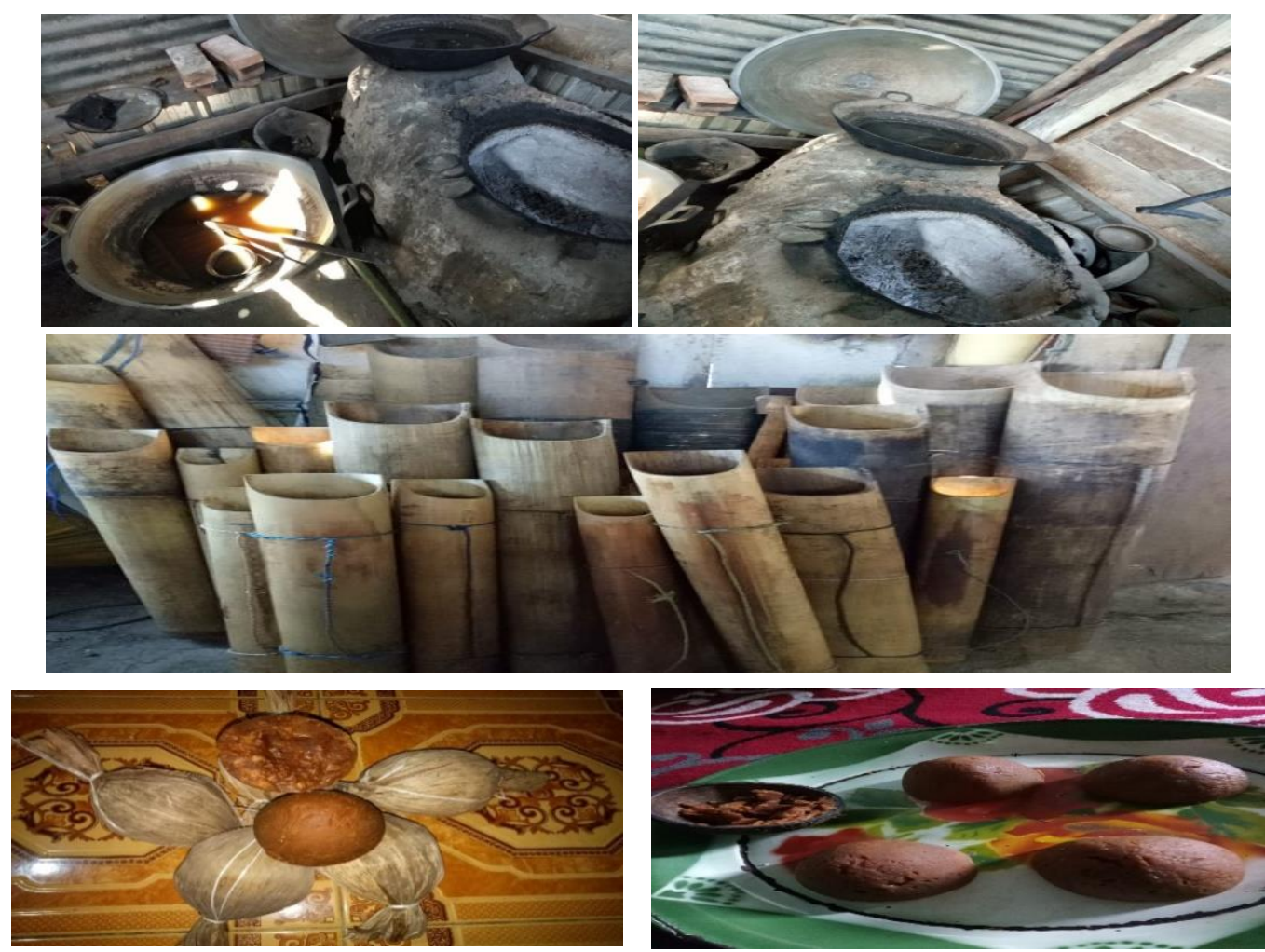

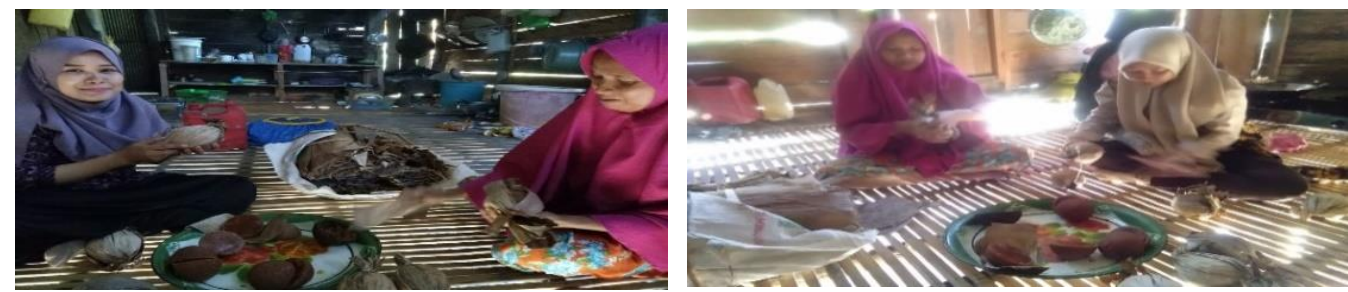

Gambar 2. Proses pengemasan dan alat pembuatan golla mamea organik

Hasil observasi juga menujukkan Produksi aren hanya diolah menjadi gula merah cetak oleh masyarakat dengan model kemasan masih sangat sederhana yang hanya terbuat dari daun pisang sehingga daya penyimpanan gula merah tidak bisa bertahan lama karena akan meleleh jika terkena udara luar. Selain itu produk tidak memiliki merk maupun label, bentuk yang dihasilkan juga monoton hanya ada satu bentuk saja. Walaupun produk gula merah bagus kualitasnya tetapi tidak didukung dengan manajemen kemasan yang menarik maka nilai jual gula merah tidak dapat dimaksimalkan padahal jika kelola dengan baik persoalan terbatasnya jangkauan wilayah pemasaran akan dapat teratasi. Jika hal ini terus dibiarkan berlarut maka potensi yang ada di Kabupaten Polman tidak akan terekspos dengan lebih maksimal. Padahal produk tersebut sangat layak untuk menjadi salah satu produk unggulan daerah yang dapat dibudidayakan, selain dapat dijadikan campuran bahan-bahan pembuatan kue-kue juga dapat digunakan sebagai oleh-oleh saat berkunjung ke Sulawesi Barat. Oleh karena itu Tim pengabdi melakukan kegiatan pelatihan dan pendampingan Ibu-ibu wanita tani terkait dengan pengolahan nira menjadi gula merah dengan adanya pengolahan dan tata cara pengemasan yang baik maka permasalahan waktu simpan gula akan teratasi dan sekaligus juga dapat menghasilkan produk yang lebih bernilai ekonomis dan meningkatkan pendapatan masyarakat atau kelompok Ibu-ibu wanita tani di Desa Mosso.

\section{Metodologi}

Dalam rangka melaksanakan solusi yang ditawarkan untuk mengatasi permasalahan mitra yaitu pada ibu-ibu wanita tani Desa Mosso Kecamatan Balanipa Kabupaten Polewali Mandar tim pengabdian masyarakat Universitas Sulawesi Barat akan menempuh langkahlangkah berikut:

1. Melakukan koordinasi dengan Kepala desa Mosso dan mendiskusikan topik yang ingin dilaksanakan

2. Melakukan pertemuan dengan kelompok wanita tani dan sosialisasi pelaksanaan program kemitraan masyarakat stimulus di Desa Mosso.

3. Melaksanakan pelatihan pengemasan dan aneka produk yang disertai dengan praktik pembuatannya secara bersama-sama sampai pada pengemasannya.

Adapun materi yang akan diberikan terkait Pemeliharaan pohon aren / Pertanian Aren, Inovasi kemasan Produk sebagai Strategi Pemasaran Produk Golla Mamea, Pemasaran Digital melalui Aplikasi

4. Pendampingan KWT (kelompok wanita tani) melalui monitoring dan Evaluasi 
Adapun skema pelaksanaan usulan kegiatan ini dapat dilihat pada gambar 3.

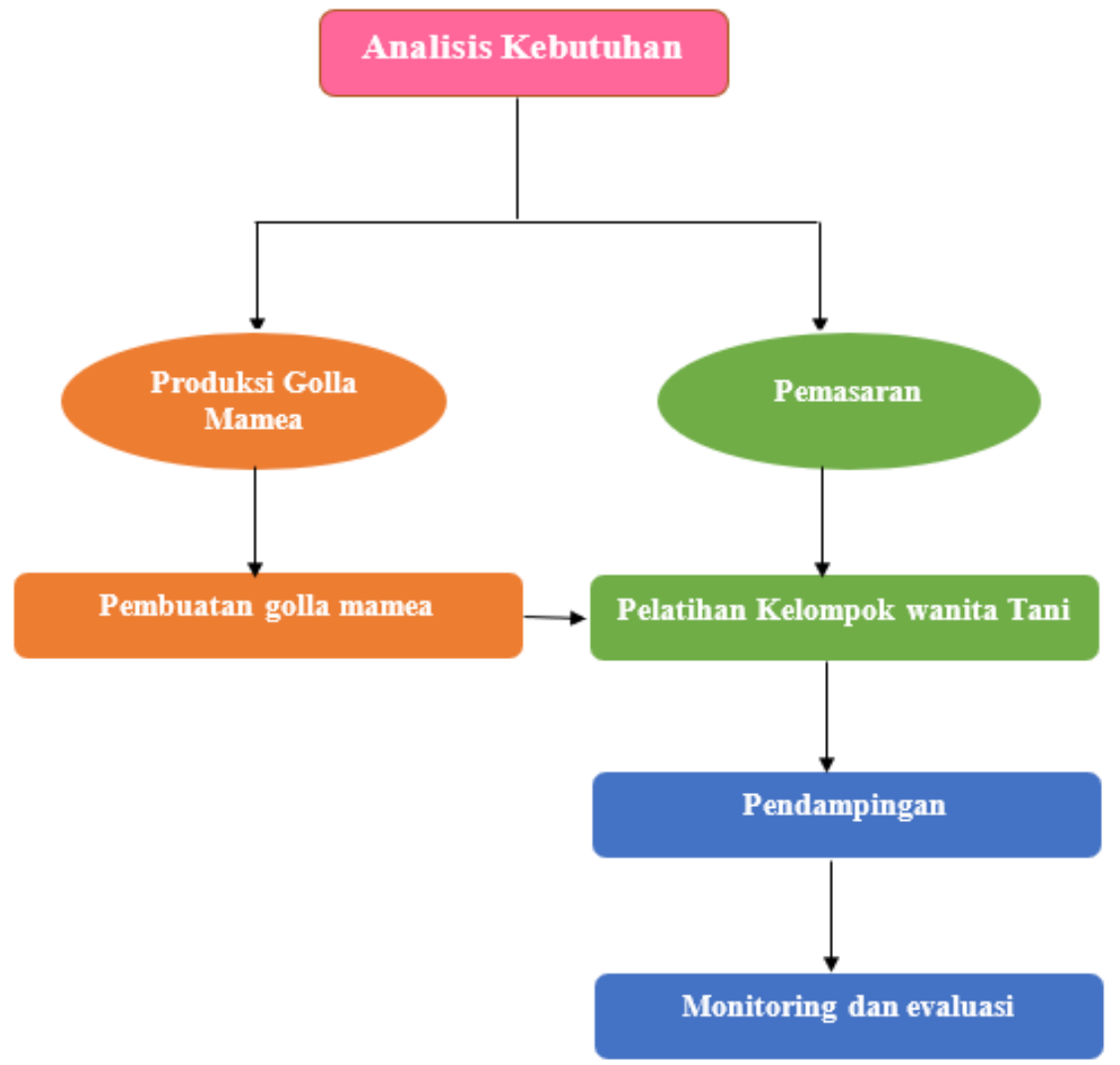

Gambar 3. Skema Pelaksanaan Program kemitraan Masyarakat Stimulus

Secara detail proses pelaksanaan yang dilakukan sebagai berikut:

\section{Penyiapan Sarana Produksi Golla Mamea}

\section{Panen Air Nira dari pohon aren}

Bahan dasar dalam pembuatan golla mamea adalah air nira, maka hal yang paling penting disiapkan diawal adalah panen air nira dari pohon nira, hal ini sudah menjadi kegiatan sehari-hari masyarakat desa mosso di pagi hari dan sore hari, hal yang pertama-tama dilakukan ialah pemasangan bambu yang sudah dibersihkan terlebih dahulu untuk menyadap air nira dari tongkol bunga jantan pada pohon aren.

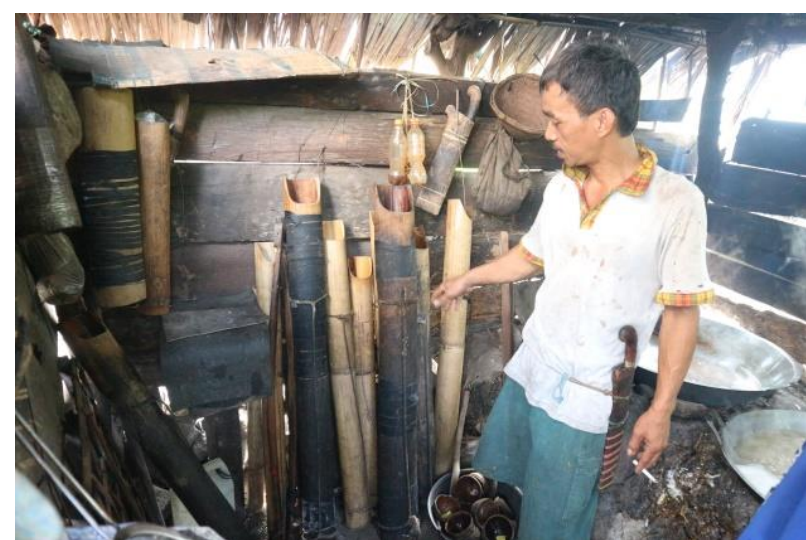

Gambar 4. Hasil panen Air nira dalam Bambu wadah tempat penyimpanan 
Gambar 4 diatas menunjukkan wadah tempat penyimpanan air nira yang telah dipanen. Cara penyadapan dilakukan dengan memotong tandan bunga jantan dengan menggunakan parang, setelah itu diletakkan bambu khusus untuk menampung air nira yang menetes, agar kondisi bambu kuat maka bambu diikat dengan pangkal tandan. Kegiatan penyadapan air nira ini dapat dilakukan 2 kali dalam sehari, nira yang di panen sejak pagi hari dapat diambil pada sore hari kemudian nira yang telah dipanen sejak sore hari dapat diambil di pagi hari berikutnya.

\section{Membuat Golla Mamea dari Air Nira}

Golla mamea merupakan pemanis yang dapat diolah menjadi aneka kue-kue, kecap manis, dodol, Baye' Mandar dan masih banyak olahan lain yang dapat dibuat dari bahan golla mamea. Berikut ini disajikan prose memasak air nira yang menjadi salah satu proses dalam pembuatan gula aren.

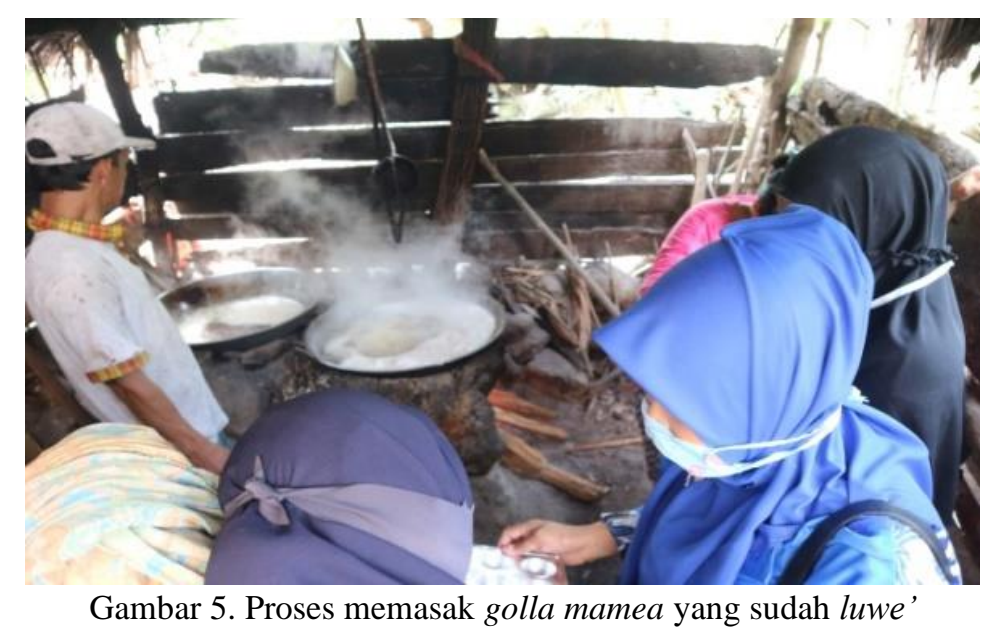

Langkah awal dalam pembuatan Golla mamea ialah mempersiapkan air nira dengan bahasa lokal manyang yang telah dipanen kemudian disaring dan masukkan ke dalam wajan. Nira dimasak dengan suhu yang stabil dan konstan biasanya dimasak dengan menggunakan bahan-bakar kayu bakar untuk mendapatkan cita rasa golla mamea yang khas, namun dapat pula menggunakan kompor seribu mata dengan bahan bakar gas. Lama waktu memasak tergantung dari volume air nira yang dimasukkan.

Air nira yang dimasak di aduk hingga mengental dan berubah warna atau dengan bahasa lokal manisang, selanjutnya diaduk dengan cara cepat dan arah memutar, pada proses ini dinamakan manggasai. Setelah gula telah mengental dan warnanya berubah menjadi kemerahan maka langkah selanjutnya dituangkan ke dalam cetakan, waktu yang dibutuhkan sampai gula menjadi padat dalam kisaran 10 menit. Cetakan yang digunakan dapat berupa tempurung kelapa, potongan bambu atau cetakan dari bahan stainles sesuai dengan ukuran yang diinginkan. Setelah gula mengeras, maka dapat segera dikeluarkan dari cetakan, agar proses penyimpanan gula tidak melengket antara satu gula dengan lainnya maka gula dialasi dengan daun pisang tua atau mengering.

\section{Membuat Kemasan}

Dalam membuat desain kemasan perlu untuk kita memperhatikan daya tahan simpan produk dan meghasilkan produk yang menarik pasar konsumen. Langkah awal dalam membuat desain produk ialah mengenali produk Golla mamea terlebih dahulu dan meberi brand atau label produk, dan perlu diperhatikan kepada siapa produk ini akan dipasarkan dan 
dimana rencana tempat penjualan produk golla mamea ini diharapkan bisa menembus pasar modern, Pada pengemasan produk dilakukan dengan 2 packaging yaitu Outer Packaging yang menjadi pandangan pertama untuk pelanggan karena bena-benar menjadi tampilan yang dapat dilihat dari luar dan konsumen dapat memperoleh informasi mengenai masa kadaluarsa dan informasi produk lainnya, outer packaging untuk golla mamea dapat berupa brown kraft paper, Kardus kotak, plastik PLA atau alumunium foil dengan beberapa ukuran, pada outer packaging juga ditempelkan merk atau brand yang telah didesain. Selanjutnya Inner packaging juga diberikan untuk memberikan perlindungan dari outer packaging agar tidak mudah lecet dan kedap udara agar daya tahan produk golla mamea lebih awet, bahan yang dipakai untuk inner packaging dapat berupa plastik bening atau daun pisang yang sudah tua atau mongering, berikut merupakan penyajian golla mamea dalam bentuk kemasan yang lama dan yang baru setelah dilakukan program pengabdian
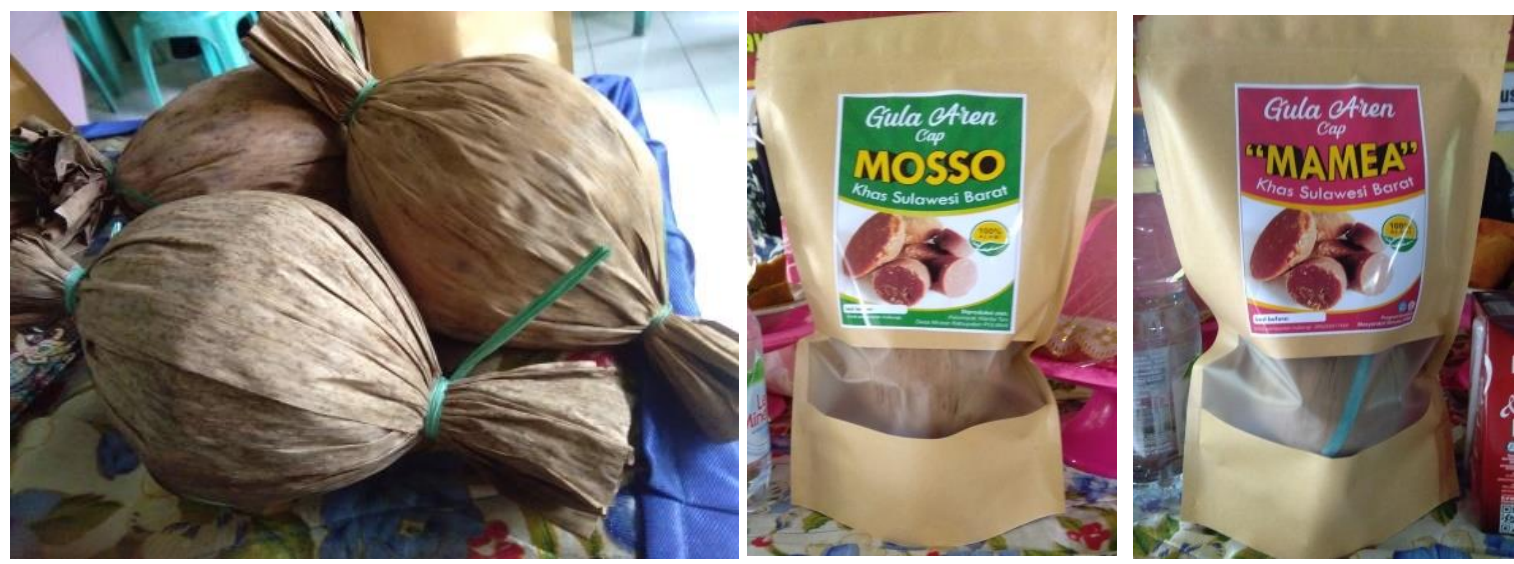

Gambar 6. Kemasan Golla Mamea Sebelum dan setelah PKMS

\section{Pelatihan Kelompok Wanita Tani}

Melalui kegiatan pendidikan, penyuluhan dan pemberian motivasi, diberikan informasi dan penyampaian mengenai pentingnya pemasaran melalui kemasan yang menarik, selain itu dengan mengemas produk secara baik kita juga dapat memperoleh manfaat lain yaitu produk memiliki daya tahan simpan yang lebih awet. Adapun materi-materi pelatihan yang isampaikan meliputi budidaya pertanian aren, Strategi pemasaran dan menumbuhkan jiwa wirausaha tani serta pemasaran digital melalui aplikasi.

Pelatihan dilaksanakan di balai kantor desa Mosso. Adapaun narasumber dari pelatihan ini merupakan kolaborasi dosen dengan bidang keilmuan ekonomi/akuntansi dengan bidang keilmuan pertanian sehingga materi yang tersampaikan dapat lebih menyeluruh dengan bahasa yang mudah dipahami oleh warga setempat selaku peserta. Dalam kegiatan pelatihan akan dilakukan demonstrasi pengemasan dan pemasaran golla mamea.Berikut merupakan gambaran pada saat proses pelaksanaan pelatihan. 


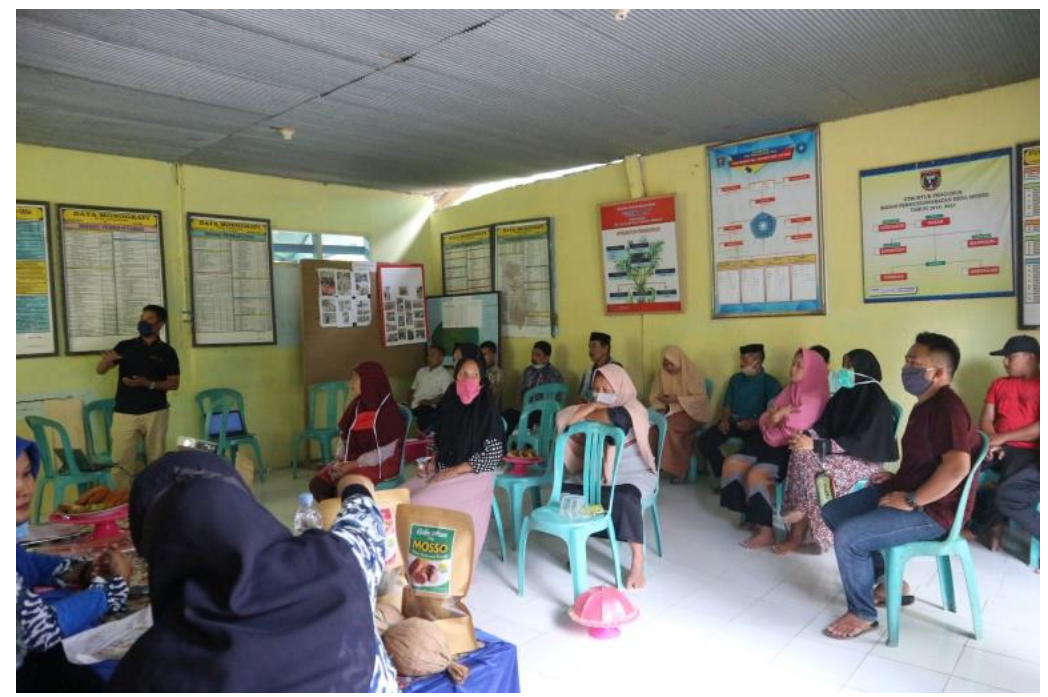

Gambar 7. Pelaksanaan Pelatihan

\section{Pendampingan, Monitoring dan Evaluasi}

Setelah dilakukan pendidikan, pelatihan dan demonstrasi, selanjutnya dilakukan pembinaan secara berkelanjutan di lokasi pengabdian dan memonitor untuk mengetahui keberhasilan dari masing-masing kelompok kerja tersebut. Berikut merupakan gambaran pelaksanaan proses monitoring sebagai salah satu proses pelaksanaan pengabdian

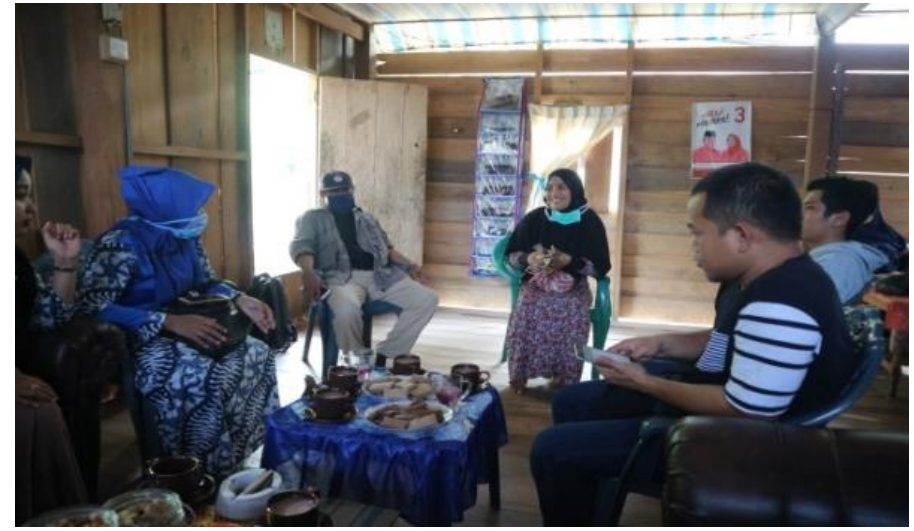

Gambar 8. Pendampingan, Monitoring \& Evaluasi

Hasil monitoring dijadikan sebagai bahan evaluasi ditindaklanjuti, yakni dengan memantapkan hal-hal yang masih dianggap kurang. Kemudian masing-masing kelompok sasaran menyebar luaskan ilmu yang telah mereka ketahui kepada warga lainnya untuk juga dipraktikkan dalam pengolahan Golla mamea. Golla mamea yang sudah dibuat dikemas sesuai dengan kebutuhan produsen dan konsumen. Setelah pelatihan, pendampingan dan monitoring dilakukan KWT diharapkan akan lebih mandiri dan melanjutkan pelaksanaanya.

Dalam rangka menjaga kualitas pelaksanaan program kemitraan masyarakat maka tim pelaksana pengabdian disesuaikan bidang keahliannya dengan tema yang diangkat dalam pengabdian kepada masyarakat ini berdasarkan prinsip "The Right Man on The Right Place". Tim bengabdian merupakan dosen Universitas Sulawesi Barat yang saling mendukung secara tekhnis dan manajemen. Bidang keahlian pengabdi berasal dari bidang ekonomi Akuntansi dan Agribisnis/pertanian. Bidang Agribisnis/Pertanian memberikan pemahaman kepada para peserta mengenai pengolahan gula merah dengan baik dan budidaya pohon aren yang 
diusahatanikan sehingga petani tidak hanya berharap dari pohon aren yang tumbuh secara alami namun juga hasil budidaya. Selanjutnya tim yang lain dengan latar belakang keilmuan Akuntansi dan manajemen memberikan pemahaman dan pengetahuan tentang pengemasan dan pemasaran bagi mitra pengabdian. Kegiatan Pengabdian ini juga melibatkan 2 orang mahasiswa yang juga mendalami ilmu akuntansi dan manajemen.

\section{Hasil dan Pembahasan}

\section{A. Hasil}

Hasil Capaian setelah pelaksanaan kegiatan ini berupa capaian dalam jangka pendek dan jangka panjang berupa:

1. Melalui pelatihan ini Ibu- ibu wanita tani sebagai pengolah gula merah mendapatkan pengetahuan dan keterampilan mengenai inovasi pengemasan golla mamea dengan demikian, nantinya produk golla mamea Desa Mosso Kabupaten Polman ini menjadi lebih menarik dan memiliki daya tahan simpan serta memperluas pemasaran golla mamea, selain itu juga penambahan wawasan mengenai pertanian atau budidaya aren sebagai bahan dasar dalam memproduksi golla mamea.

2. Jangka panjang ibu-ibu wanita tani dalam jangka panjang dapat membuat usaha baru berbentuk home industries sehingga pendapatan keluarga dapat meningkat.

Peningkatan nilai ekonomi dari produk golla mamea dilakukan dengan meberikan kemasan yang lebih menarik serta memiliki daya tahan simpan yang lebih lama sehingga dapat menarik daya beli konsumen di pasaran, Secara detail berikut disajikan peningkatan nilai jual golla mamea.

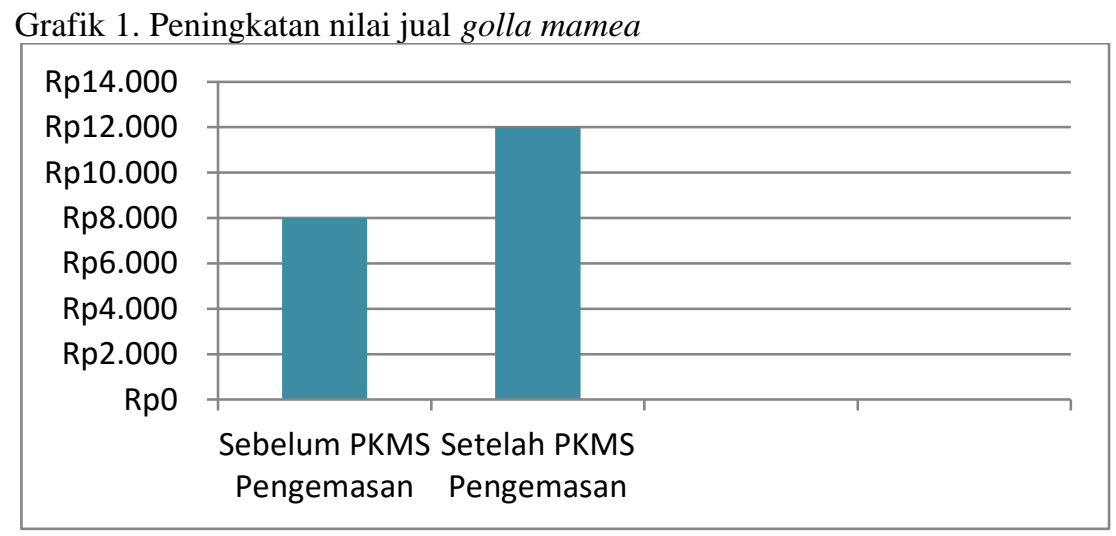

Upaya pelaksanaan program pengabdian ini dilakukan sejalan dengan hasil penelitian yang dilakukan oleh Lubis, (2017) yang menyatakan bahwa salah satu strategi pemasaran dalam industri rumah tangga gula aren ialah membuat kemasan yang higienis dan lebih menarik dari pada produk lain yang sejenis.

Program pengabdian atau kegiatan sejenis dengan program ini juga pernah dilakukan oleh Soesanto et al., (2014) dan dalam kesimpulannya mengemukakan bahwa terjaminnya keamanan kemasan serta terlihat lebih menarik akan menjadikan nama produk gula aren lebih baik dan dengan demikian konsumen juga akan lebih percaya pada saat pemilihan produk gula aren, desain kemasan juga menjadi sarana penting dalam melakukan promosi produk yang memiliki banyak pesaing. 
Peningkatan sosial ditunjukkan dengan bertambahnya pemahaman masyarakat desa Mosso mengenai budidaya pertanian aren sehingga dapat memberikan motivasi untuk lebih memelihara warisan pertanian aren nenek moyang sebagai bahan dasar pembuatan golla mamea, disamping itu juga semakin meluasnya pemasaran golla mamea yang awalnya hanya pada kawasan lokal setempat, dengan adanya pemahaman pemasaran melalui sosial media ataupun aplikasi, kelompok pembuat golla mamea dapat mencoba memasarkan produknya tidak hanya dengan sistem dari mulut ke mulut.

Dalam pelaksanaan PKMS ini, kelompok sasaran terlibat secara langsung dalam pelatihan pemasaran dan pengemasan, sehingga setelah kegiatan ini selesai, kelompok sasaran tersebut dapat mandiri dalam menjalankan kegiatan usaha taninya. Keterlibatan kelompok sasaran mulai pada persiapan bahan, perlengkapan maupun peralatan yang dibutuhkan pada kegiatan pelatihan, sampai pada keterlibatan dalam membuat gula merah, mengemas dan memberinya label sendiri sehingga mereka dapat melakukan hal itu secara mandiri pasca pelatihan selesai dilakukan.

Pemerintah desa Mosso juga menunjukan kontribusi, apresiasi dan antusias atas pelaksanaan program kemitraan stimulus ini dengan memberikan izin untuk pelaksanaan pelatihan untuk kelompok mitra di balai kantor desa Mosso kecamatan balanipa kabupaten polewali mandar, adapun waktu pelaksanaan pelatihan pada hari kamis. 6 Agustus 2020. Pelatihan ini diikuti oleh sekertaris desa, para kepala dusun yang ada di desa Mosso, ketua kelompkok wanita tani Melati, para anggota kelompok wanita tani dan perwakilan warga dari 3 dusun yang ada di des Mosso yaitu Dusun Mosso, Dusun Naung Landi dan Dusun Pangalloang.

Adapun kontribusi mitra secara rinci diuraikan seperti dalam Tabel 2 berikut.

Tabel 2. Partisipasi Mitra dalam Kegiatan PKMS

\begin{tabular}{|c|c|c|c|}
\hline No & Tahapan Kegiatan & Jenis Kegiatan & Bentuk Partisipasi Mitra \\
\hline 1 & Sosialisasi Kegiatan & Pertemuan kelompok & $\begin{array}{l}\text { Memberikan tanggapan (kritik dan masukan) } \\
\text { dalam diskusi }\end{array}$ \\
\hline 2 & $\begin{array}{l}\text { Perencanaan } \\
\text { Pelatihan }\end{array}$ & Pertemuan Kelompok & $\begin{array}{l}\text { 1. Menetapkan jadwal kegiatan } \\
\text { 2. Menetapkan Lokasi Kegiatan pelatihan }\end{array}$ \\
\hline 3 & Pelaksanaan kegiatan & $\begin{array}{l}\text { Pelatihan/ } \\
\text { muka }\end{array}$ & $\begin{array}{l}\text { 1. Sebagai peserta dalam kegiatan pelatihan } \\
\text { 2. Menyiapkan sebagian bahan dan perlatan } \\
\text { yang akan digunakan } \\
\text { 3. Berpartisipasi aktif dalam kegiatan diskusi } \\
\text { atau tanya jawab }\end{array}$ \\
\hline 4 & Pelaksanaan kegiatan & $\begin{array}{l}\text { Demonstrasi/ } \\
\text { Simulasi Pengemasan } \\
\text { Produk }\end{array}$ & $\begin{array}{l}\text { 1. Menyiapkan bahan dan peralatan yang akan } \\
\text { digunakan dalam kegiatan pengemasan } \\
\text { produk }\end{array}$ \\
\hline & & & $\begin{array}{l}\text { 2. Melaksanakan pengembangan konsep } \\
\text { design kemasan } \\
\text { 3. Melaksanakan simulasi pengemasan produk } \\
\text { golla mamea }\end{array}$ \\
\hline 5 & $\begin{array}{l}\text { Pendampingan / Monitoring- } \\
\text { Evaluasi }\end{array}$ & $\begin{array}{lr}\text { Pertemuan } & \text { Kelompok } \\
\text { dan } & \text { Tinjauan } \\
\text { Lapangan } & \\
\end{array}$ & $\begin{array}{l}\text { 1. Diskusi Kelompok } \\
\text { 2. Berpartisipasi dalam pelaksanaan } \\
\text { monitoring dan evaluasi pelaksanaan PKMS }\end{array}$ \\
\hline
\end{tabular}

\section{Simpulan}

Pengabdian kepada masyarakat denga skema program kemitraan masyarakat stimulus ini dilakukan pada Desa Mosso dengan kelompok wanita tani desa Mosso sebagai mitra, Pengabdian ini dilakukan guna peningkatan nilai jual golla mamea yang merupakan produk 
khas desa Mosso. Kegiatan pengabdian telah dilakukan dimulai dari sosialisasi dan pertemuan kelompok mitra, pelaksanaan simulasi pengemasan, pelaksanaan pelatihan serta monitoring dan evaluasi. Upaya peningkatan nilai jual dilakukan dengan membuat inovasi kemasan golla mamea yang sebelumnya hanya menggunakan kemasan sederhana dari daun pisang kering kemudian di buat inovasi baru dengan sentuhan label dan brown paper craft sebagai cover luar untuk meningkatkan daya tarik pembeli dan menjaga kebersihan serta daya tahan produk, kemudian dilakukan pula upaya perluasan pasar. Selain itu diberikan pula penambahan wawasan mengenai budidaya pertanian aren sebagai bahan dasar dalam pembuatan golla mamea yang merupakan warisan nenek moyang. Nilai jual golla mamea sebelumnya dengan kemasan daun pisang sederhana seharga Rp 8000 setelah adanya inovasi kemasan dapat dijual hingga harga Rp 13.000. kemudian diharapkan selanjutnya desa mitra dapat dengan mandiri melakukan perluasan pasar dan inovasi produk.

Golla mamea merupakan produk uggul yang diminati masyarakat sebagai bahan dasar dalam pembuatan berbagai bentuk kuliner khas Sulawesi, oleh karenanya para pembuat golla mamea dapat membuat inovasi terbaru lagi dari produk gula merah bukan hanya terbatas pada bentuk cetak namun bisa pula dibuat dalam bentuk serbuk ataupun cair. Pemasaran produk dapat lebih diperluas lagi, Kemudian untuk pemerintah desa Mosso dapat menjadikan produk golla mamea ini sebagai produk yang lebih berkembang dan lebih unggul melalui kerja sama Badan Usaha Milik Desa (Bumdes).

\section{Ucapan Terima Kasih}

Kegiatan pengabdian kepada masyarakat ini didanai oleh Hibah Kementrian Riset dan Teknologi/ Badan Riset dan Inovasi Nasional melalui Lembaga Penelitian dan Pengabdian pada Masyarakat Universitas Sulawesi Barat dengan Surat Perjanjian T/033/UN55.C/KP.00.5/2020.

\section{Daftar Pustaka}

A. Sapari. (1994). Teknik Pembuatan Gula Aren. Karya Anda.

BPS. (2016). Badan Pusat Statistik Kabupaten Polewali Mandar. Badan Pusat Statistik.

Lempang, M. (2006). RENDEMEN DAN KANDUNGAN NUTRISI NATA PINNATA YANG DIOLAH DARI NIRA AREN. Jurnal Penelitian Hasil Hutan. https://doi.org/10.20886/jphh.2006.24.2.133-144

Lempang, M. (2012). Pohon Aren dan Manfaat Produksinya. Info Teknis EBONI.

Lubis, R. (2017). Analisis Strategi Pemasaran Usaha Gula Aren. REPOSITORY UNIVERSITAS MEDAN AREA.

http://repository.uma.ac.id/handle/123456789/9553?mode=full

S. Soeseno. (1991). Bertanam Aren. P.T. Penebar Swadaya,.

Soesanto, L. A., Tanudjaja, B. B., B, B. S., Studi, P., Komunikasi, D., Seni, F., Petra, U. K., \& Siwalankerto, J. (2014). Produksi Desa Margolelo Rowoseneng. Jurnal DKV Adiwarna, Universitas Kristen Petra, 1(4), 1-12. http://publication.petra.ac.id/index.php/dkv/article/view/2016

A. Sapari. (1994). Teknik Pembuatan Gula Aren. Karya Anda.

BPS. (2016). Badan Pusat Statistik Kabupaten Polewali Mandar. Badan Pusat Statistik.

Lempang, M. (2006). RENDEMEN DAN KANDUNGAN NUTRISI NATA PINNATA

YANG DIOLAH DARI NIRA AREN. Jurnal Penelitian Hasil Hutan. https://doi.org/10.20886/jphh.2006.24.2.133-144 
Lempang, M. (2012). Pohon Aren dan Manfaat Produksinya. Info Teknis EBONI.

Lubis, R. (2017). Analisis Strategi Pemasaran Usaha Gula Aren. REPOSITORY UNIVERSITAS MEDAN

AREA. http://repository.uma.ac.id/handle/123456789/9553?mode=full

S. Soeseno. (1991). Bertanam Aren. P.T. Penebar Swadaya,.

Soesanto, L. A., Tanudjaja, B. B., B, B. S., Studi, P., Komunikasi, D., Seni, F., Petra, U. K., \& Siwalankerto, J. (2014). Produksi Desa Margolelo Rowoseneng. Jurnal DKV Adiwarna, Universitas Kristen Petra, 1(4), 1-12. http://publication.petra.ac.id/index.php/dkv/article/view/2016 